\title{
Infraestrutura Econômica no Brasil: uma Análise de sua Relevância sob a Ótica de Matriz Insumo-Produto
}

\section{Economic Infrastructure in Brazil: an Analysis of its Relevance from the Point of View of the Input-Output Matrix}

\author{
Geovana Lorena Bertussi ${ }^{\mathrm{a}}$ \\ Milene Takasago ${ }^{\mathrm{a}}$ \\ Joaquim José Martins Guilhoto ${ }^{\mathrm{b}}$
}

\begin{abstract}
Resumo: Diante da necessidade de ampliação dos investimentos no país na atual conjuntura da economia brasileira e da compreensão dos efeitos positivos dos investimentos em infraestrutura, torna-se relevante o estudo dos efeitos multiplicadores desse tipo específico de investimento sobre os demais setores da economia do país. Para isso, o presente estudo utiliza a metodologia de matriz insumo-produto, dados de 2011 . São calculados os índices de Rasmussen-Hirschman, que evidenciam o grau de encadeamento dos setores econômicos, considerando que há ligação tanto para trás quanto para frente. Também são apresentados os campos de influência para cada setor. Os resultados evidenciam que os setores de transporte e eletricidade podem ser considerados estratégicos para o crescimento e desenvolvimento da economia brasileira.
\end{abstract}

Palavras-chave: Infraestrutura. Matriz insumo-produto. Crescimento e desenvolvimento econômico.

\begin{abstract}
In view of the need to expand investments in the country, in the current context of the Brazilian economy, and understanding the positive effects of investments in infrastructure, it is relevant to study the multiplier effects of this specific type of investment on the other sectors of the country's economy. For this, the present study used the inputoutput matrix methodology, using data from 2011. The Rasmussen-Hirschman indices, which show the degree of linkage of the economic sectors, were calculated, considering that there is a connection both backwards and forwards. The fields of influence were also presented for each sector. The results show that the Transportation and Electricity sectors can be considered strategic for the development of the Brazilian economy.
\end{abstract}

Keywords: Infrastructure. Input-output matrix. Economic development and growth.

JEL Classification: C67; H54; O18.

a Universidade de Brasília (UnB), Faculdade de Economia, Administração, Contabilidade e Gestão de Políticas Públicas (FACE), Departamento de Economia. Brasília, Distrito Federal, Brasil.

b Universidade de São Paulo (USP), Faculdade de Economia, Administração e Contabilidade (FEA), Departamento de Economia. São Paulo, São Paulo, Brasil. 


\section{1 lntrodução}

Em 2015, a taxa de crescimento da economia foi de $-3,8 \%$, pior resultado do PIB desde 1990. Em 2016, o resultado também foi negativo, -3,6\%, colocando o país em recessão por dois anos consecutivos, o que não acontecia desde a crise de 19301931, quando os recuos foram menores do que os verificados recentemente. Como a retração atual é maior, verifica-se a pior crise histórica já registrada na economia brasileira (INSTITUTO BRASILEIRO DE GEOGRAFIA E ESTATÍSTICA, 2017).

Nesse contexto, o retorno do crescimento econômico é um desafio. Economistas apontam a necessidade de aumento do investimento na economia nacional (tanto do ponto de vista público quanto privado). Contudo, a taxa de investimento total em relação ao PIB apresentou declínio pelo terceiro ano seguido em 2016, alcançando 16,4\%, o menor valor desde 1996, quando o IBGE iniciou o cálculo de sua série histórica.

Em especial, os investimentos em infraestrutura apresentaram contração importante no ano de 2015, em relação a 2014. Os dados oficiais de 2016 ainda não estão disponíveis no site da Associação Brasileira da Infraestrutura e Indústrias de Base (Abdib), mas a associação prevê queda também para o ano de 2016. De acordo com a Abdib, em 2015 o investimento total, público e privado, em infraestrutura diminuiu em todos os subsetores: transportes, telecomunicações, energia elétrica e saneamento. Essa queda deve-se, principalmente, à redução nos investimentos públicos, fruto da deterioração da situação fiscal do Estado, observada de forma mais contundente desde 2014, ano em que o país passou a apresentar déficits primários anuais, o que não havia acontecido até então. Como os investimentos são despesas discricionárias, sofreram os cortes mais pesados do governo para a promoção do ajuste fiscal.

Entretanto, há vasta literatura que corrobora os efeitos positivos dos investimentos em infraestrutura no crescimento econômico dos países e também do Brasil (trabalhos expostos na revisão bibliográfica, mais adiante). Ademais, no caso de investimentos em infraestrutura, há complementariedade entre gastos públicos e privados, ou seja, um efeito crowding-in, em que maiores gastos públicos no setor reduziriam custos logísticos e outros custos que compõem o Custo Brasil, atraindo maior monta de investimentos do setor privado, que poderia produzir e escoar sua produção de modo mais eficiente, alavancando sua produtividade e tornando-a mais competitiva.

Desse modo, diante da necessidade de ampliação dos investimentos, na atual conjuntura da economia brasileira, e da compreensão dos efeitos positivos dos investimentos em infraestrutura, torna-se relevante o estudo dos efeitos multiplicadores desse tipo específico de investimento sobre os demais setores da economia do país. Para isso, o presente estudo utiliza a metodologia de MIP, dados de 2011. 
São calculados os índices de Rasmussen-Hirschman, que evidenciam o grau de encadeamento dos setores econômicos, considerando que há ligação tanto para trás quanto para frente. Também são apresentados os campos de influência. Os resultados evidenciam que os setores de transporte e eletricidade podem ser considerados estratégicos para a economia brasileira.

O artigo, além desta introdução, está dividido em mais quatro seções. A seção 2 faz uma análise teórica e empírica sobre a relevância da infraestrutura para a produtividade e para o crescimento, apresentando resultados empíricos de outros países e também para o caso específico brasileiro. A seção 3 mostra os métodos e procedimentos utilizados. A seção 4 explica os resultados da pesquisa. Por fim, a seção 5 traça as considerações finais.

\section{Revisão de Literatura}

Nesta seção falaremos a respeito da importância teórica da infraestrutura para crescimento e produtividade dos países e das regiões, bem como apresentaremos alguns estudos empíricos relacionados ao tema de infraestrutura e matriz insumo-produto.

\subsection{Base Teórica: Teorias de Crescimento e Economia das Novas Instituições}

Durante grande parte do século XX, a temática do crescimento econômico dos países foi assunto recorrente. Essa preocupação com o desempenho das economias mundiais esteve presente em vários momentos, mas em especial podemos listar: após a Primeira Guerra Mundial; depois da quebra da Bolsa de Nova Iorque em 1929; após a Segunda Guerra Mundial; durante os anos 1970 (com as crises do petróleo em 1973 e 1979); no decorrer dos anos 1980 (em especial nos países da América Latina, que vivenciavam um período de grande endividamento e falência fiscal do Estado); e, mais recentemente (já no século XXI), a crise do subprime nos Estados Unidos e suas consequências para todo o globo.

Concomitantemente a essa trajetória de grandes variações na atividade econômica mencionada no parágrafo anterior, foram-se desenvolvendo teorias voltadas à questão do crescimento econômico de longo prazo dos países e quais seriam seus determinantes. Uma contribuição seminal nesse sentido foi a de Solow (1956), que mostra que o crescimento de longo prazo está diretamente ligado ao crescimento da produtividade. Utilizando uma função de produção do tipo Cobb-Douglas, o autor mostra que, por apresentarem retornos decrescentes, incrementos de capital e/ou trabalho são capazes de gerar crescimento durante um período de transição para um novo equilíbrio estável. Após alcançar um novo estado estacionário, mais crescimento seria possivel somente mediante ganhos de produtividade. 
Entretanto, no modelo de Solow (1956) a produtividade é uma variável exógena, ou seja, um parâmetro não determinado e nem modificado por outras variáveis presentes no próprio modelo. Dessa forma, se o principal determinante do crescimento de longo prazo dos países é o avanço de sua produtividade, isso ainda era uma caixa-preta no modelo solowiano.

Se o crescimento de longo prazo é determinado pelo crescimento da produtividade, então o que determina o crescimento da produtividade?

Foi nesse contexto e com esse propósito que surgiram as contribuições da chamada nova teoria do crescimento ou teoria do crescimento endógeno, cujos principais expoentes são Romer (1986, 1990) e Lucas (1988). Lucas (1988) atribuiu ao capital humano a importante tarefa de elevar a produtividade de uma economia e, com isso, contribuir para seu crescimento de longo prazo. Para o autor, o acúmulo de capital humano seria um mecanismo sustentável gerador de melhor desempenho econômico, ou seja, em economias nas quais os indivíduos investissem mais tempo estudando ou aprendendo e aprimorando determinada atividade (no sentido a la Arrow (1962) de learning by doing), a produção seria maior e mais próxima à fronteira tecnologicamente eficiente, proporcionando maior riqueza.

Romer $(1986,1990)$ respondeu de duas maneiras ao questionamento levantado anteriormente. Para ele, considerando sua primeira contribuição à teoria do crescimento endógeno em 1986, a produtividade pode ser ampliada devido às externalidades positivas associadas ao estoque de capital físico acumulado. Já no artigo de 1990, fica claro que também a produtividade pode ser determinada pelos investimentos em pesquisa e desenvolvimento (PED), fazendo com que a economia tenha maior potencial inovador. Com mais frequentes e/ou maiores inovações tecnológicas, os processos produtivos ficam mais eficientes, um maior aproveitamento é dado aos insumos, elevando a produtividade e promovendo maior crescimento econômico. Nesse último ponto, fica clara a semelhança entre o artigo de Romer (1990) e o de Lucas (1988) ao focarem na importância da contribuição do capital humano para o crescimento de longo prazo das economias, seja por meio de mais pesquisa e gerando novas ideias, seja por meio de externalidades positivas associadas ao maior conhecimento.

Nos anos 1990, ganhou força a teoria de que as instituições importam (NOR$\mathrm{TH}, 1990$ ). A economia das novas instituições, como ficou conhecida, trouxe ao centro da discussão econômica o impacto positivo que instituições robustas e confiáveis podem ter sobre o crescimento econômico de um país. Instituições seriam definidas, de acordo com North (1990), como sendo as regras do jogo, ou seja, todo tipo de normas formais e informais que restringem o comportamento dos agentes econômicos. Nesse sentido, a teoria novo-institucionalista é uma contribuição em si mesma, mas ao mesmo tempo também um complemento importante às teorias de crescimento econômico, engrandecendo a discussão e trazendo novas perspectivas à análise de desempenho de longo prazo dos países. 
Um dos teóricos institucionalistas é Coase (1992). Sua contribuição à ciência econômica foi considerar em sua análise dois aspectos básicos negligenciados pelos demais estudiosos da área: a existência de custos de transação positivos para o processo de produção das firmas e a importância dos direitos de propriedade bem definidos pelo Estado. Ao avaliar esses pontos, Coase percebeu as significativas implicações que isso traria para a estrutura da teoria econômica. Para o autor, a partir do momento em que se analisa uma sociedade com custos de transação não nulos, o seu sistema de regras e leis formais torna-se imediatamente de grande relevância para toda a cadeia produtiva. Os direitos que os indivíduos possuem são, na maioria das vezes, o que a lei determina. Assim sendo, as normas terão um efeito bastante profundo sobre o funcionamento do sistema econômico e a alocação dos recursos disponíveis, uma vez que afetarão os incentivos privados e os custos de transação da economia.

O artigo de Acemoglu, Johnson e Robinson (2001) corrobora a explanação de Coase (1992) ao afirmar que, em países com menores riscos de expropriação (ou seja, países com direitos de propriedade bem estabelecidos e respeitados), haveria ganhos significativos em termos de renda per capita. Acemoglu, Johnson e Robinson (2004) argumentam, em outro trabalho, que as instituições determinam os incentivos econômicos dos agentes, influenciando as decisões produtivas, de investimento e de acumulação de capital físico e humano, o que traria impactos não somente na eficiência produtiva (tamanho do bolo) como também na sua distribuição entre a população, ou seja, as instituições (tanto políticas quanto econômicas) seriam a causa fundamental nas diferenças de crescimento econômico entre países.

Inserida na análise da economia das novas instituições está ainda a discussão a respeito da importância regulatória, suas características e implicações sobre a performance econômica. Levy e Spiller (1996) mostram em seu livro que é importante haver restrições sobre a discricionariedade regulatória, bem como restrições a mudanças no sistema regulatório e instituições que reforcem os dois aspectos para que haja um desempenho satisfatório em termos do regulador, com resultados positivos sobre o setor regulado e a economia como um todo.

\subsection{Infraestrutura, Produtividade e Crescimento Econômico}

Tendo discutido brevemente a base teórica concernente às teorias de crescimento econômico, bem como a economia das novas instituições, qual a relação dessas contribuições analisadas anteriormente com a temática de infraestrutura?

A infraestrutura econômica pode ser definida, de acordo com o BID (2000, p. 13, como "[...] o conjunto de estruturas de engenharia e instalações - geralmente de longa vida útil - que constituem a base sobre a qual são prestados os serviços considerados necessários para o desenvolvimento produtivo, político, social e pes- 
soal [...]". Visto dessa maneira, a infraestrutura é o estoque de capital físico sobre o qual são prestados serviços como o de telefonia celular, transporte de cargas, abastecimento de água, entre outros. Se infraestrutura pode ser traduzida em maior estoque de capital, então a relação da infraestrutura com as teorias de crescimento econômico é direta, uma vez que maior acumulação de capital leva a maior nível de produto no longo prazo (SOLOW, 1956). Além disso, se um maior estoque de capital gera externalidades positivas, conforme apontado por Romer (1986), mais infraestrutura levaria a um maior crescimento do produto no longo prazo, isso sem falar nos efeitos indiretos que uma infraestrutura mais abundante e de melhor qualidade traria sobre a produtividade da economia.

Ainda, se a ampliação da infraestrutura estiver associada à investimentos em PEBD e inovação tecnológica (como no caso de exploração de petróleo de gás na área de infraestrutura energética), isso estimularia maiores investimentos e acumulação de capital humano, levando a uma melhor performance de longo prazo na renda per capita do país, conforme apontam os trabalhos de Romer (1990) e Lucas (1988).

Com boas instituições - que garantam os direitos de propriedade, sejam transparentes, adotem freios e contrapesos, reduzam custos de transação e riscos de expropriação (COASE, 1992; ACEMOGLU; ROBINSON, 2008; ACEMOGLU; JOHNSON; ROBINSON, 2001, 2004) - e com agências reguladoras que apresentem salvaguardas para o comportamento do regulador - conforme levantado por Levy e Spiller (1996) -, os atores econômicos terão mais previsibilidade e segurança com relação ao futuro, o que reduzirá incertezas e a percepção de riscos por parte dos agentes e atrairá mais investimentos, em especial no setor de infraestrutura, que tem como premissa elevados investimentos iniciais e alongamento no tempo de retorno desse investimento. Ou seja, para o setor de infraestrutura, ter um ambiente institucional e regulatório apropriado que promova investimentos pode ser ainda mais relevante que em outros setores, devido ao grande montante inicial requerido e ao tempo dilatado de payback. ${ }^{1}$

Portanto, instituições sólidas e respeitadas em conjunto com um ambiente regulatório bem estruturado e desenhado de forma a gerar incentivos corretos para o setor de infraestrutura têm o potencial de alavancar os investimentos na área, promovendo maior acumulação de capital, impactando positivamente na produtividade e no crescimento econômico de longo prazo das economias.

Uma vez que, em termos teóricos, ficou evidenciada a relação entre infraestrutura, produtividade e crescimento econômico, o restante desta seção traz algumas contribuições empíricas, o que permitirá quantificar a importância do setor de infraestrutura para o crescimento da renda per capita em vários países e também para o Brasil.

Um trabalho empírico seminal avaliando o impacto da infraestrutura sobre a produtividade e crescimento do produto é o de Aschauer (1989). O autor analisa

$1 \quad$ Período de tempo necessário para recuperar o capital inicial investido. 
a relação entre a produtividade agregada da economia e o PIB com medidas de estoque de infraestrutura e de fluxo de gastos governamentais no setor, utilizando dados anuais, para o período compreendido entre 1949 e 1985, para os Estados Unidos. Um dos principais resultados do artigo mostra uma elasticidade do PIB em relação ao estoque de capital público no valor de $0,39 .{ }^{2}$ Outro resultado importante apresentado por Aschauer (1989) é a fraca relação entre gastos públicos e a produtividade, ou seja, o estoque de capital público tem maior importância tanto em termos de significância estatística quanto em termos de magnitude dos coeficientes estimados - do que o fluxo de gastos governamentais para explicar o crescimento do produto e a produtividade da economia americana no período estudado. Além disso, a chamada infraestrutura core - rodovias, aeroportos, gás, energia elétrica, água e saneamento - possui poder explanatório maior sobre a produtividade do que outros tipos de estoque de capital (como prédios de escritórios, estações policiais, etc.).

Calderón e Servén (2004) mostram o impacto da infraestrutura sobre o crescimento do produto e sobre a desigualdade de renda, entre 1960 e 2000, para um conjunto de 121 países, utilizando metodologias de dados em painel. Os autores utilizaram análise de componentes principais para construírem dois índices de infraestrutura: um que refletisse quantidade e outro, qualidade da infraestrutura. No índice de quantidade, foram considerados o número de linhas telefônicas a cada 1000 trabalhadores, a capacidade de geração elétrica da economia (em MW por 1000 trabalhadores) e a extensão das rodovias (em Km por $\mathrm{Km}^{2}$ de área do país). No índice de qualidade, foram contemplados o tempo de espera por uma linha telefônica (em anos), a porcentagem de perdas na transmissão e distribuição de eletricidade e a porcentagem de estradas pavimentadas no total de estradas do país.

Os autores mostraram que o crescimento é afetado de forma positiva e significante pelo índice de quantidade de infraestrutura e que a desigualdade de renda se reduz com infraestrutura mais abundante e de melhor qualidade. Desagregando o índice de quantidade de infraestrutura em seus três componentes (transportes, energia e telecomunicações), tanto o setor de transportes quanto o de telecomunicações apresentaram resultados positivos e significantes em todas as estimativas, enquanto que, no setor energético, as estimativas nem sempre se mostraram significativas estatisticamente. A qualidade da infraestrutura mostrou-se mais relevante para atenuar desigualdades de renda do que para alavancar o crescimento econômico dos países.

Ferreira e Malliagros (1998) realizam uma análise para o Brasil no período entre 1950 e 1995, inspirados pelo texto de Aschauer (1989). Os autores também analisam o impacto da infraestrutura sobre o produto e a produtividade da economia e utilizam tanto medidas de estoque quanto medidas de fluxo para mensurar

2 Os resultados são robustos a alterações no modelo básico. 
infraestrutura. Ferreira e Malliagros (1998), no entanto, usam o método de cointegração. As estimativas sugerem que um acréscimo de $1 \%$ no estoque de infraestrutura aumentaria o PIB entre $0,55 \%$ e $0,61 \%$ no longo prazo.

Ao desagregarem o estoque de capital de infraestrutura em ferrovias, portos, rodovias, energia elétrica, telecomunicações e transportes, o setor de energia foi o que apresentou maior elasticidade-PIB $(0,683 \%)$, seguido pelo setor de transportes $(0,572 \%)$ e, por último, o setor de telecomunicações $(0,428 \%)$. Com relação ao setor de transportes, a desagregação mostra os efeitos mais intensos no PIB do setor de ferrovias, seguido pelo de portos e, por último, o de rodovias. É interessante ressaltar que a maior parte dos investimentos no setor de transportes no Brasil atualmente são direcionados ao modal rodoviário.

As elasticidades do produto com relação ao investimento (também desagregado nos mesmos níveis do parágrafo anterior) são de menores magnitudes do que as elasticidades das séries de capital. Nesse caso, o setor de transportes apresenta maior elasticidade $(0,463 \%)$, seguido do setor de energia $(0,362 \%)$ e telecomunicações $(0,275 \%)$.

Outro trabalho bastante importante para o caso brasileiro é o de Mussolini e Teles (2010). Os autores afirmam que "[...] o capital de infraestrutura de um país exerce uma influência extremamente importante no processo produtivo, seja diretamente, como insumo na produção, ou indiretamente, através do impacto sobre a PTF [...]" (MUSSOLINI; TELES, 2010, p. 648). A relação entre capital de infraestrutura e produtividade no Brasil é avaliada pelo método de cointegração, no período entre 1950 e 2000. Os resultados evidenciam a relevância da infraestrutura para explicar a evolução da Produtividade Total dos Fatores (PTF) no longo prazo, sendo as estimativas robustas a diferentes mensurações, tanto da produtividade quanto do estoque de capital de infraestrutura.

Além disso, Mussolini e Teles (2010) argumentam que o declínio de investimentos no setor de infraestrutura nos anos 1980 no país podem ser uma explicação plausível para a queda da produtividade brasileira observada e documentada no mesmo período, uma vez que o sentido de causalidade é de estoque de capital de infraestrutura, afetando a PTF, mas não o oposto (pelo teste de causalidade de Granger). É conveniente ressaltar que os autores não desagregaram os dados de estoque de capital para análise em separado dos setores de infraestrutura.

Bertussi e Ellery Júnior (2012) investigam o impacto dos gastos públicos em transportes sobre o crescimento econômico dos estados brasileiros entre 1986 e 2007, utilizando metodologia de dados em painel. Além do modelo tradicional de efeitos fixos, estimam um modelo de regressão quantílica, pois apresenta uma solução para cada quantil da distribuição de renda. Dessa forma, obtêm informações mais pormenorizadas de como as variáveis independentes do modelo afetam os estados brasileiros de acordo com sua posição na distribuição de crescimento con- 
dicional, gerando informações interessantes e mais específicas a respeito de suas heterogeneidades. Os resultados obtidos mostram que o investimento público no setor de transportes provoca efeito positivo e estatisticamente significante sobre o desempenho econômico de longo prazo dos estados brasileiros e contribui potencialmente para a redução da desigualdade de renda entre eles.

Ainda de acordo com as evidências empíricas encontradas, os gastos públicos em infraestrutura de transporte foram mais produtivos nas regiões menos desenvolvidas do país (regiões Norte, Nordeste e Centro-Oeste). Portanto, os autores defendem que as políticas públicas implementadas no país são de extrema relevância para a promoção do crescimento econômico e do desenvolvimento regional brasileiro.

Conforme afirmam Estache e Fay (2007), uma análise cuidadosa da literatura econômica a respeito da relação entre infraestrutura e crescimento demonstra um consenso crescente em torno da noção da importância que a infraestrutura exerce para alavancar crescimento do produto e reduzir custos de produção e que essa relevância parece ser ainda mais expressiva em países com menores níveis de renda - como é o caso do Brasil.

\subsection{Mudança Estrutural e Crescimento Econômico}

Até o presente momento, nesta revisão de literatura, falou-se da relação entre infraestrutura, produtividade e crescimento econômico de um ponto de vista agregado, ou seja, tomando como ponto de partida um modelo neoclássico a la Solow (1956), com função de produção homogênea e considerando a economia com apenas um setor. Samuelson (1966) e Solow (1956) argumentam que o uso de funções de produção agregadas seriam uma forma analítica simplificada de representar a complexidade de um mundo com bens de capital e relações técnicas heterogêneos.

Pasinetti (1981, 1993), por sua vez, apresenta uma abordagem multissetorial na qual a composição estrutural das diferentes economias em seus distintos estágios de desenvolvimento teria influência determinante no desempenho econômico de cada uma, ou seja, alterações na estrutura produtiva importariam para o crescimento econômico agregado de um país ou região.

Echevarria (1997) também lança luz sobre essa questão das diferentes visões a respeito de mudanças na composição setorial e o produto agregado da economia. De acordo com a autora, o crescimento econômico é resultado de alterações na estrutura setorial. A partir desse trabalho, muitos outros surgiram, em especial o de Laitner (2000).

Nessa mesma linha argumentativa, McMillan e Rodrik (2011) mostram que uma economia poderia crescer mais, por exemplo, se realocasse trabalho e outros 
fatores de produção de setores de baixa para setores de alta produtividade. Desse modo, portanto, o maior crescimento seria fruto de uma mudança na composição estrutural, afetando positivamente a performance econômica.

Outro fator que poderia expandir crescimento, de acordo com Saviotti e Pyka (2004), seria a emergência de novos setores na economia, promovendo diversificação e ganhos de produtividade. Nesse ponto, Freire (2017) argumenta que são justamente os setores com maiores ganhos de produtividade (ou seja, com maior capacidade pré-existente) aqueles que estariam mais propensos a gerarem diversificação, de modo que o surgimento de novos setores e a produtividade são dois lados de um mesmo processo integrado de desenvolvimento econômico.

Apesar de, por um longo período de tempo, a teoria tradicional do crescimento ter deixado em segundo plano a perspectiva de mudanças e composição estrutural, nos últimos anos essa ideia tem ganhado folego e está sendo gradativamente incorporada à análise de crescimento econômico. Tanto do ponto de vista da demanda (com elasticidades renda da demanda diferentes pra cada setor) quanto do ponto de vista da oferta (diferenças setoriais na evolução da produtividade), mudanças estruturais importam para o crescimento de longo prazo de uma nação. Recentemente, uma nova onda de modelos de crescimento tem desenvolvido melhores formas de analisar o processo de mudança estrutural, e, além disso, alguns modelos têm, inclusive, conciliado mudança estrutural com modelos de crescimento agregados. Esses modelos contribuem para o melhor entendimento dos mecanismos por trás da relação entre composição setorial e crescimento econômico (GABARDO; PEREIMA; EINLOFT, 2017). Arena (2017) também reforça a relevância e a adequabilidade do uso de modelos agregados mesmo na presença de mudanças estruturais.

Tendo em vista o exposto, proceder-se-á a revisão de literatura especializada, por setores de infraestrutura, utilizando-se uma matriz insumo-produto (MIP) para a economia brasileira.

\subsection{Infraestrutura e Matriz Insumo-Produto}

Considerando-se a metodologia de MIP e sua relação com o setor de infraestrutura, outra base teórica ganha destaque no campo econômico: a análise de Hirschman (1961) de desenvolvimento desequilibrado. De acordo com o autor, a economia cresceria de modo não linear, de forma que alguns setores teriam destaque, puxando outros setores da economia, e esse processo dinâmico e contínuo levaria a um efeito de crescimento do produto. O sucesso desse fenômeno e o aumento de produção de um setor daria incentivos a outros setores da economia, fazendo com que a renda da economia como um todo se acelerasse. Os efeitos de encadeamento seriam tanto prospectivos quanto retrospectivos, ou seja, há rever- 
berações para frente e para trás nas cadeias produtivas. Dessa forma, investimentos em infraestrutura teriam o potencial de gerar investimentos em outros setores, induzindo novas inversões e ampliando a renda da economia.

Nesse contexto, Toyoshima e Ferreira (2002) avaliam a magnitude dos encadeamentos do setor de transportes sobre o crescimento da economia brasileira. Eles definem setor-chave como sendo aquele que apresenta, em média, mais efeitos de encadeamentos - tanto para frente quanto para trás - de modo que investimentos nesse setor levariam, em média, a maiores efeitos sobre a economia do que a investimentos em setores alternativos - definição compartilhada por Guilhoto e Sesso Filho (2005).

Ainda de acordo com os autores, setores com alto impacto de encadeamento para frente e para trás teriam elevado potencial de gerar externalidades positivas sobre a renda, de modo que as políticas públicas deveriam focar seus recursos escassos nesses setores. Como não há recursos para inversões em todos os setores ao mesmo tempo (o que é notório na atual conjuntura da economia brasileira), identificar setores-chave seria fundamental para priorizar investimentos em áreas mais importantes.

Partindo desse pressuposto, os autores calculam dois índices que mostram se os efeitos de encadeamentos para frente e para trás do setor de transportes no Brasil, no período entre 1990 e 1999, são mais elevados do que a média dos demais setores da economia. Os resultados mostram que apenas os efeitos de encadeamento para frente do setor de transportes são, em média, maiores do que os demais setores da economia, o que evidencia a relevância do setor de transportes como indutor de crescimento econômico no país, no período analisado.

Oliveira e Teixeira (2006) usaram a mesma metodologia de Toyoshima e Ferreira (2002) e buscaram identificar setores-chave para a economia brasileira (entre os setores de transporte, energia e telecomunicações) a partir dos dados da MIP de 1996. Os resultados mostraram concordância com Toyoshima e Ferreira (2002), ou seja, o setor de transporte apresentou somente efeito de encadeamento para frente maior do que um, indicando que um grande conjunto de outros setores da economia brasileira dependem do desempenho do setor logístico no país.

Com relação ao setor energético, o resultado foi similar ao setor de transportes, qual seja, o índice de encadeamento para frente foi maior que a média dos setores da economia, mas o mesmo não ocorreu com o índice de encadeamento para trás. De acordo com Guilhoto (1995), mesmo setores que só apresentem efeitos de encadeamento para frente ou para trás (e não ambos ao mesmo tempo) maiores do que a média podem ser considerados setores-chave para a economia, num conceito menos rígido do que considerar apenas como setores-chave os que apresentem ambos os encadeamentos maiores que a média. Portanto, de acordo com essa definição mais branda e flexível, os setores de transporte e energia pode- 
riam ser classificados como setores-chave para a economia brasileira, por apresentarem índices de ligação para frente maiores do que a média dos demais setores.

O setor de telecomunicações não é considerado um setor-chave nem nesse conceito mais brando, uma vez que apresentou índices de ligação para frente e para trás menores do que a unidade. Tanto esse último resultado de Oliveira e Teixeira (2006) relativo ao setor de comunicações quanto o resultado relativo ao setor de transportes (que apresentou somente índice de ligação para frente superior à unidade) são análogos aos obtidos por Haddad e Perobelli (2002) também para esses setores, mas utilizando uma MIP com dados de 1985. Haddad e Perobelli (2002) não fizeram a análise desagregada para o setor de energia.

Portanto, tendo em vista os resultados descritos, uma análise mais recente sobre os efeitos de encadeamento dos setores de transportes, telecomunicações e eletricidade sobre a economia brasileira, utilizando o instrumental de MIP, seria de grande importância. Ressalta-se que os trabalhos analisados, sobre a aplicação do instrumental insumo-produto para avaliar as relações intersetoriais da infraestrutura na economia brasileira, referem-se às MIPs estimadas, utilizando a metodologia de elaboração das Contas Nacionais ${ }^{3}$ de 1995 ou 2000 (INSTITUTO BRASILEIRO DE GEOGRAFIA E ESTATÍSTICA, 2017). Atualmente, o IBGE utiliza a metodologia de 2010 para a construção das Contas Nacionais, na qual, dentre outras mudanças, destaca-se a abertura do setor de transportes, telecomunicações ${ }^{4}$ e energia elétrica, gás natural e outras utilidades. Isso torna a análise sobre os efeitos da infraestrutura na economia brasileira mais precisa, permitindo avaliar com mais eficiência e confiabilidade os seus efeitos. Neste trabalho, foi também realizada a desagregação do setor de energia elétrica do setor de energia elétrica, gás natural e outras utilidades, o que não foi observado em trabalhos anteriores. Desse modo, a proposta deste trabalho não é somente atualizar dados da MIP, mas também fazer uma avaliação mais precisa sobre a composição dos subsetores que compõem o setor de infraestrutura, na sua maioria, definidos e calculados pelo IBGE.

Além das inovações sobre os dados mais recentes para estimação da MIP, vale ressaltar que, após 2002, ${ }^{5}$ vários programas de governo foram lançados no intuito de aprimorar a infraestrutura no país, tal como o Programa de Aceleração do Crescimento 1 (PAC 1), o PAC 2, o Programa de Investimento em Logística (PIL) e, mais recentemente, o Programa de Parceria de Investimentos (PPI). É de interesse para o país avaliar os efeitos desses investimentos sobre os setores de infraestrutura e também os impactos destes sobre os demais setores da economia. Isso será realizado por meio da construção de uma MIP mais recente, ano 2011,

3 Os dados utilizados para estimar as matrizes de insumo-produto são as tabelas de recursos e usos de bens e serviços, calculadas pelo IBGE.

$4 \quad$ Esse setor foi desagregado do setor de serviços de comunicações.

5 Trabalhos anteriores não captam os possíveis impactos, pois referem-se a períodos anteriores aos PACs. 
em que alguns setores foram desagregados para que fosse possível avaliar o setor de infraestrutura. Por meio dos indicadores derivados da MIP, serão analisados os efeitos de encadeamentos da infraestrutura na economia brasileira.

\section{Metodologia}

As próximas subseções apresentarão os métodos e procedimentos que seguimos neste artigo, como o cálculo da matriz insumo-produto e seus índices de ligação e campo de influência correspondentes.

\subsection{Estimação da Matriz Insumo-Produto}

O modelo de insumo-produto foi desenvolvido por Leontief (1951), o qual permite identificar as variações ocorridas na produção total da economia dado uma variação na demanda final. Esse modelo considera que a relação entre os insumos demandados em cada setor ou atividade e a produção total desse setor é constante, permitindo determinar uma matriz denominada de matriz de coeficientes técnicos.

Neste trabalho, estima-se uma matriz com, inicialmente, 149 setores e 128 produtos, para o ano de 2011. A fim de se alcançar os objetivos propostos nesta pesquisa, foram realizadas agregações, restringindo a matriz para 14 setores, a saber: a) agricultura, pecuária, produção florestal, pesca e aquicultura; b) indústrias extrativas; c) indústrias de transformação; d) eletricidade; e) gás, água, esgoto, atividades de gestão de resíduos e descontaminação; f) construção; g) comércio, reparação de veículos automotores e motocicletas; h) transporte; i) armazenamento, correios e atividades auxiliares dos transportes de carga e passageiros; j) serviços de informações; k) telecomunicações; l) intermediação financeira, seguros e previdência complementar; m) outras atividades de serviços; n) administração pública, defesa, seguridade social, saúde e educação pública. Assim sendo, a infraestrutura econômica foi composta pelos setores de eletricidade, transportes e telecomunicações. Vale ressaltar que os dados fundamentais utilizados para a estimação da MIP2011 são as tabelas de recursos e usos (INSTITUTO BRASILEIRO DE GEOGRAFIA E ESTATÍSTICA, 2017), e estas não contemplam o setor de eletricidade desagregado. Com isso, esse setor foi determinado a partir de uma desagregação do setor de eletricidade e gás, usando dados da Pesquisa Industrial Anual (PIA), Pesquisa Nacional de Amostra Domiciliar (PNAD), Pesquisa Anual de Serviços (PAS) e Pesquisa de Orçamento Familiar (POF), entre outros.

A metodologia de estimação da MIP 2011 foi baseada nas propostas apresentadas por Guilhoto e Sesso Filho (2005). Inicialmente, realizou-se a compatibilização entre as matrizes de usos e recursos de bens e serviços, divulgadas pelo IBGE (INSTITUTO BRASILEIRO DE GEOGRAFIA E ESTATÍSTICA, 2015). Isso foi 
necessário porque a matriz de usos de bens e serviços apresenta os dados a preços de mercado, enquanto a matriz de recursos de bens e serviços considera a preço básico.

Na proposta de estimação de Guilhoto e Sesso Filho (2005), parte-se, inicialmente, das tabelas de usos e recursos divulgadas pelo IBGE, para 68 setores e 128 produtos. A tabela de usos possui valores a preços de mercado, que devem ser transformados a preços básicos. Portanto, torna-se necessário subtrair da oferta global, que apresenta os valores a preço de mercado, os valores referentes às margens de comércio (MGC) e de transporte (MGT), Imposto sobre Circulação de Mercadorias e Serviços (ICMS), Impostos sobre Produtos Industrializados (IPI), Impostos sobre Serviços (ISS), outros impostos indiretos líquidos (OIIL), importação de bens e serviços (IMP) e impostos de importação (IIMP) de cada produto para cada setor de atividade.

Uma das dificuldades para estimar a matriz de usos a preços básicos é distribuir os valores totais de impostos e margens nessa matriz. A metodologia proposta por Guilhoto e Sesso Filho (2005) estabelece que seja calculada a matriz de distribuição, que consiste em estimar coeficientes a serem multiplicados pelos diversos setores e produtos da economia. Esses coeficientes são determinados pela seguinte equação:

$$
\alpha_{i j}=\frac{Z_{i j}}{\sum_{j=1}^{n} Z_{i j}}
$$

Na equação $1, Z_{i j}$ indica a quantidade do produto $i$ que foi vendida para o setor $j$ a preços de mercado, e $\sum_{j=1}^{n} Z_{j}$ representa o valor total do produto i vendido para todos os setores da economia e para a demanda final, em que n é o número de setores da economia.

Os valores totais das margens e impostos, presentes na tabela de recursos de bens e serviços divulgadas pelo IBGE (INSTITUTO BRASILEIRO DE GEOGRAFIA E ESTATÍSTICA, 2017), são distribuídos internamente entre os produtos produzidos na economia, multiplicando esses valores pelos coeficientes encontrados na equação 1. Assim, são estimadas as matrizes de MGC, MGT, ICMS, IPI/ISS e OIIL.

A demanda final é composta pela soma do consumo final, investimento e exportações. Dessa forma, para implementarmos a metodologia mencionada será necessário subtrair as exportações, isto é, zerar a coluna que contém seus valores. Em seguida, define-se uma nova demanda final e total. Usa-se o mesmo processo metodológico para encontrar as matrizes para IMP e IIMPs. O passo seguinte é fazer as subtrações e, assim, transformar a matriz de usos a preço de mercado em preço básico. 
Tendo-se as matrizes de usos e recursos de bens e serviços a preço básico, utiliza-se a metodologia proposta por Miller e Blair (2009) e Guilhoto e Sesso Filho (2005) para se calcular a MIP 2011.

A partir das compras intermediárias, segundo Tosta, Lírio e Silveira (2004) e Miller e Blair (2009), e os valores brutos da produção, pode-se obter a matriz de coeficientes técnicos $-A=\left(a_{i j}\right)$. Esses coeficientes são determinados pela equação 2:

$$
a_{i j}=\frac{f_{i j}}{X_{j}}
$$

em que $f=\left(f_{i j}\right)$ é matriz de consumo intermediário, ou seja,indica a quantidade de insumos que o setor $\mathrm{j}$ comprou do setor $i$, e $X_{j}$ é a produção total do setor $j$.

O modelo estático de Leontief, segundo Miller e Blair (2009), descreve os fluxos intersetoriais, são determinados tanto por fatores econômicos quanto tecnológicos e podem ser descritos como um sistema de equações simultâneas.

Em termos matriciais, o fluxo intersetorial em uma economia pode ser representado por:

$$
A X+Y=X
$$

em que $\mathrm{A}=\left(\mathrm{a}_{\mathrm{ij}}\right)$ é a matriz de coeficientes diretos de insumos e $\mathrm{X}$ é a produção total do setor. $O$ vetor $Y$ contém a demanda final.

Tratando-se a demanda final como exógena ao sistema, tem-se:

$$
\begin{gathered}
X=B Y \\
B=(I-A)^{-1}
\end{gathered}
$$

em que $B=\left(b_{i j}\right)$ é a matriz de coeficientes diretos e indiretos, ou matriz inversa de Leontief. O elemento $b_{i j}$ deve ser interpretado como a produção total do setor $i$ que é necessária para produzir uma unidade de demanda final do setor $j$.

\section{2 Índices de Ligações}

A partir do modelo de Leontief, equação 4, e seguindo-se Rasmussen (1956) e Hirschman (1961), pode-se calcular os índices de ligação para trás - que definem o quanto um determinado setor demanda de insumos para produzir uma unidade 
monetária - e para frente - que fornecem informações sobre o quanto o setor fornece de insumos para os demais setores da economia.

Os índices de ligações são determinados a partir da matriz inversa de Leontief. $B=\left(b_{i j}\right)$ é a matriz inversa de Leontief, isto é, $B=(I-A)^{-1}$, e $\mathrm{B}^{*}$ é a média de todos os elementos de $B$; e $B_{*_{j}}$ é a soma de uma coluna típica de B. Portanto, o índice de ligação para trás (ILT), a partir dos elementos da matriz inversa de Leontief, pode ser definido pela equação:

$$
I L T_{j}=\left[B_{* j} / n\right] / B^{*}
$$

Com relação ao índice de ligação para frente (ILF) e para avaliarmos a importância do setor de infraestrutura na economia brasileira, a metodologia utilizada foi a de Ghosh, segundo Miller e Blair (2009). Essa metodologia evidencia a importância de cada setor como fornecedor de insumos ao restante da economia. A definição do índice segue as equações seguintes. Inicialmente, definiu-se:

$$
T=\frac{f_{i j}}{x_{i}}
$$

Desse modo, define-se $T$ como sendo a matriz de coeficientes técnicos da linha obtida a partir da matriz de consumo intermediário da economia. Sendo $G$ a matriz de Ghosh obtida pela fórmula $G=(I-T)^{-1}$ (MILLER; BLAIR, 2009), $G^{*}$, a média de todos os elementos de $G$ e $G_{i^{*}}$, a soma de uma linha típica de $G$, tem-se, então, os seguintes índices de ligações para frente:

$$
I F L_{i}=\left[\mathrm{G}_{i *} / \mathrm{n}\right] \mathrm{G}^{*}
$$

Os índices de ligação mensuram o efeito de encadeamento de um determinado setor com o restante da economia. Então, de acordo com Miller e Blair (2009), a classificação de um determinado setor pode ser feita de acordo com o Quadro 1. 
Quadro 1 - Classificação dos setores de acordo com seus índices de ligações

\begin{tabular}{|l|l|l|}
\hline Índice de ligação & ILF $>1$ & ILF $<1$ \\
\hline ILT $>1$ & Setor-chave & $\begin{array}{l}\text { Depende da oferta dos demais } \\
\text { setores }\end{array}$ \\
\hline ILT $<1$ & $\begin{array}{l}\text { Depende da demanda dos demais } \\
\text { setores }\end{array}$ & Independente \\
\hline
\end{tabular}

Fonte: Elaboração própria a partir de Miller e Blair (2009).

\subsection{Campo de Influência}

O campo de influência tem por objetivo avaliar como mudanças nos coeficientes técnicos diretos podem ser distribuídas por todas as atividades econômicas. Portanto, por meio desses indicadores pode-se estabelecer os setores com maior influência no sistema econômico.

Para se calcular o campo de influência, utiliza-se a matriz de coeficientes técnicos, $A=\left[a_{i j}\right]$, e a variação incremental no coeficiente direto de insumo, $E$ $=\left[\varepsilon_{i j}\right]$, considerando-se a matriz inversa de Leontief, $B=[I-A]=b_{i}$ e definindo $B(\varepsilon)=[\mathrm{I}-\mathrm{A}-\varepsilon]^{-1}$.

Caso ocorra uma pequena mudança em apenas um coeficiente técnico, somente este coeficiente receberá a variação, isto é, $\varepsilon_{i j}=\varepsilon$ se $i=i_{1}, j=j_{1}$ e, para os outros setores não haverá mudanças, ou seja, $\varepsilon_{i j}=0$ para $i \neq i_{l}, j \neq j_{1}$. Então, segundo Guilhoto et al. (1994), a equação 9 evidencia o campo de influência:

$$
\mathrm{F}=\left(\varepsilon_{i j}\right)=\left[\mathrm{B}\left(\varepsilon_{i j}\right)-\mathrm{B}\right] / \varepsilon_{i j}
$$

em que $\mathrm{F}=\left(\varepsilon_{i j}\right)$ é uma matriz $(n \times n)$ que mede o efeito sobre os demais coeficientes, dada uma variação no coeficiente $a_{i j}$. A equação 10 tem como finalidade obter o valor dos coeficientes que possuem maior campo de influência, associados a cada matriz, $\mathrm{F}\left(\varepsilon_{i j}\right)$ :

$$
S_{i j}=\sum_{k=1}^{n} \sum_{l=1}^{n}\left[f_{k l}\left(\varepsilon_{i j}\right)\right]^{2}
$$

Por fim, os coeficientes diretos que apresentarem maiores valores de $S_{i j}$ serão os de maior campo de influência no sistema econômico. 


\section{Análise dos Resultados}

O Quadro 2 apresenta os índices de Rasmussen-Hirschman para trás (ILT) e para frente (ILF) e também o ranking dos setores, com relação crescente de acordo com os maiores indicadores. Segundo Guilhoto e Sesso Filho (2005), os setores que apresentarem ILT e ILF maiores que uma unidade são considerados setores-chave ou estratégicos para o desenvolvimento da economia. De acordo com os dados do Quadro 2, os setores que apresentaram fortes ligações para trás se destacaram como importantes compradores de insumos e os que apresentaram fortes ligações para frente, ou seja, setores importantes como fornecedores de insumos para a economia como um todo, foram os setores da indústria de transformação, eletricidade e transportes.

Quadro 2 - Indicadores de Rasmussen-Hirschman

\begin{tabular}{|c|l|c|c|c|c|}
\cline { 3 - 6 } \multicolumn{2}{l|}{} & ILT & Rank & ILF & Rank \\
\hline 1 & Agropecuária & 0,99 & 7 & 1,12 & 4 \\
\hline 2 & Extrativa mineral & 0,91 & 11 & 1,07 & 6 \\
\hline 4 & Indústria de transformação & 1,26 & 1 & 1,00 & 9 \\
\hline 5 & Eletricidade & 1,08 & 5 & 1,27 & 1 \\
\hline 6 & Gás, água e esgoto & 1,00 & 6 & 1,04 & 7 \\
\hline 7 & Construção & 1,12 & 3 & 0,65 & 13 \\
\hline 8 & Transporte & 0,91 & 12 & 0,93 & 11 \\
\hline 9 & $\begin{array}{l}\text { Armazenamento, correios e atividades auxiliares dos } \\
\text { transportes de carga e passageiros }\end{array}$ & 1,13 & 2 & 1,17 & 3 \\
\hline 10 & Serviços de informação & 0,94 & 8 & 1,27 & 2 \\
\hline 11 & Telecomunicações & 0,93 & 9 & 1,08 & 5 \\
\hline 12 & $\begin{array}{l}\text { Intermediação financeira, seguros e previdência } \\
\text { complementar }\end{array}$ & 1,10 & 4 & 0,96 & 10 \\
\hline 13 & Outros serviços & 0,93 & 10 & 1,01 & 8 \\
\hline 14 & $\begin{array}{l}\text { Administração pública, defesa , seguridade social, saúde } \\
\text { e educaçáo pública }\end{array}$ & 0,83 & 13 & 0,88 & 12 \\
\hline
\end{tabular}

Fonte: Elaboração própria.

Destacam-se, portanto, os setores de infraestrutura, eletricidade e transportes como estratégicos para o crescimento da economia. Vale ressaltar que o conjunto de setores da economia depende desses setores, seja no fornecimento de insumos, seja como demandantes dos produtos fabricados em outros setores, e, para que não ocorram estrangulamentos, caso haja um aumento na demanda final, esses setores precisam aumentar suas produções mais que a média da economia. 
Também como são chaves como demandantes dos demais setores, caso haja um crescimento nos setores de transportes e eletricidade, aumentando suas demandas finais, o impacto nos demais setores será acima da média da economia.

Com os resultados apresentados no Quadro 2, pode-se concluir que os setores que compõem a infraestrutura estão com os maiores ranks, seja com maiores ILT ou ILT. Nesse sentido, como fornecedores de insumos destacam-se eletricidade (primeira posição) e transportes (segunda posição). Com relação ao consumo de bens intermediários, destacam-se transportes em segundo lugar, telecomunicações em quarto e eletricidade em quinto.

Embora o setor de telecomunicações não seja estratégico, pois seu ILF é menor que a unidade, apresentou um forte encadeamento como fornecedor de insumos, como visto anteriormente.

A análise proposta por Rasmussen-Hirschman pode ser também complementada por meio do campo de influência. Como definido anteriormente, o campo de influência tem como objetivo identificar como as mudanças nos coeficientes técnicos diretos são distribuídas na economia como um todo. Assim, para se medir esses efeitos, foi considerada uma pequena variação na matriz dos coeficientes técnicos diretos e analisado como se espalharam no sistema econômico, determinando-se quais relações entre os setores são mais relevantes no processo produtivo. Essas relações são ilustradas na Figura 1.

Figura 1 - Campo de influência

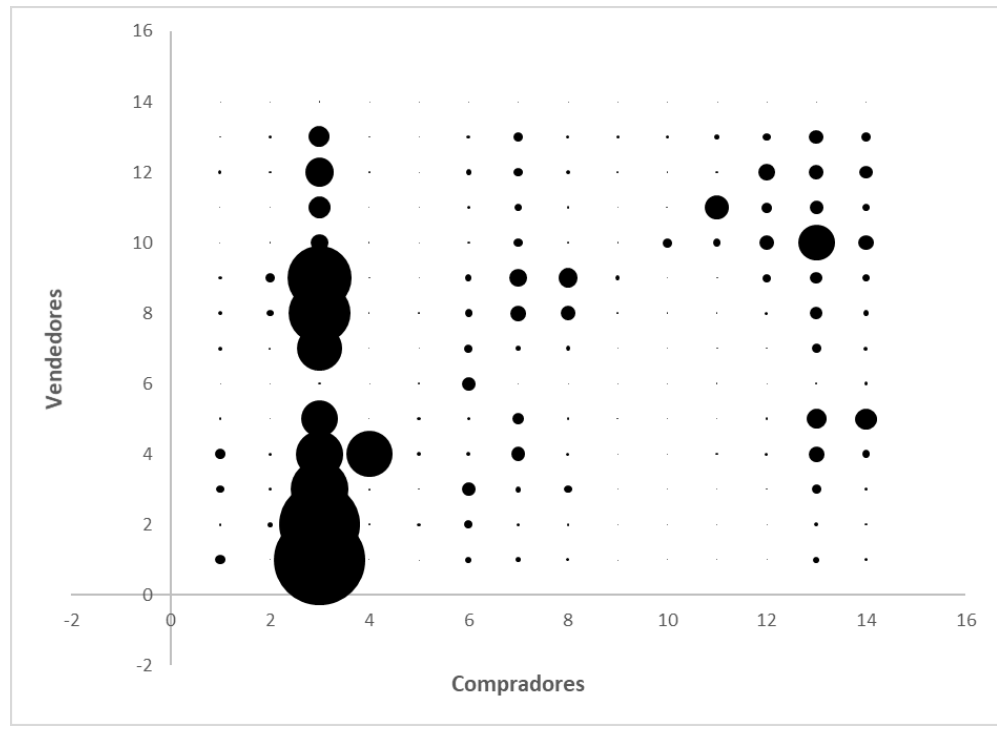

Fonte: Elaboração própria. 
Pode-se verificar que, caso ocorra pequenas alterações nos coeficientes diretos de produção, a indústria de transformação (3) seria a maior compradora de insumos dos demais setores. Analisando-se os setores como fornecedores de insumos, percebe-se que os setores de eletricidade (4) e transportes (8) aparecem como um dos grandes propagadores, visto que existem muitos setores para os quais fornecem insumos. Também é possível verificar a magnitude das interações entre setores por meio da área de cada bolha, conforme ilustrado na Figura 1. Portanto, é possível observar que o maior coeficiente setorial é o da indústria de transformação com ela mesma e que também há uma forte relação de demanda de insumos com os setores de transportes e eletricidade.

Os resultados sobre os efeitos dos setores de transporte e eletricidade na economia brasileira não somente confirmam, de forma metodologicamente robusta, a importância desses setores, como possibilitam dar uma magnitude desses efeitos, seja na comparação média com os demais setores, seja na determinação de valores que permitam fazer um ranking entre os setores. Tais medidas são fundamentais para orientar os elaboradores de políticas públicas quanto à importância de priorizar esses setores para o bom funcionamento da economia.

Essas análises de impactos, entre as relações setoriais da economia, corroboram com as conclusões mencionadas nas seções anteriores sobre a importância do desenvolvimento da infraestrutura para impulsionar o crescimento de setores fundamentais da economia, tal como, a Indústria de Transformação.

\section{Considerações Finais}

Este trabalho avaliou os efeitos de encadeamento para trás e para frente dos setores de infraestrutura econômica brasileiros (transportes, energia elétrica e telecomunicações), bem como seus campos de influência, utilizando a metodologia de MIP calculada para o ano de 2011. Os cálculos dos índices de encadeamento para trás e para frente demonstram que os setores de transporte e eletricidade apresentam-se como setores-chave da economia, ou seja, apresentaram índices maiores que a unidade tanto para frente quanto para trás, o que significa que tiveram desempenho maior que a média, tanto na demanda por insumos de outros setores, quanto no fornecimento de insumos para os demais setores produtivos. O setor de telecomunicações, por sua vez, apresentou índice de encadeamento para trás maior do que a unidade, mas o índice de encadeamento para frente é menor do que um (valor calculado de 0,96). Em relação ao campo de influência, percebeu-se que o setor de eletricidade, dentre os setores de infraestrutura econômica avaliados, parece ter maior efeito propagador na economia do país, seguido pelos setores de telecomunicações e transportes. 
Os resultados alcançados neste artigo reforçam a importância dos setores de infraestrutura, notadamente os setores de transportes e eletricidade, para a geração de efeitos multiplicadores positivos sobre a taxa de crescimento do Brasil. Investir mais é condição necessária fundamental para alavancar o desempenho da economia brasileira. Em especial, percebe-se que investimentos em infraestrutura econômica têm um papel ainda mais estratégico para o país, pois possuem efeitos de espalhamento acima da média para vários outros setores.

Para destravar os investimentos em infraestrutura, o atual governo tem trabalhado no Programa de Parcerias de Investimentos (PPI) - também chamado de Projeto Crescer - a fim de melhorar o cenário macroeconômico, dar segurança jurídica e maior previsibilidade ao investidor, garantir taxas de retorno adequadas à realidade do mercado, reduzir entraves burocráticos, repensar modelos atuais de concessões, entre outras medidas.

O objetivo do PPI, de modo geral, é promover maior participação privada na ampliação com qualidade da oferta de infraestrutura e de seus serviços, com preços e tarifas adequados tanto para o consumidor quanto para o ofertante/concessionário. Os primeiros leilões dos projetos anunciados pelo governo em setembro de 2016 foram realizados em 2017, como, por exemplo, o caso dos aeroportos e linhas de transmissão de energia. Há, ainda, um cronograma extenso para acontecer com concessões previstas em rodovias, portos, ferrovias, petróleo e gás, usinas e distribuidoras de energia, etc.

Espera-se que todo o esforço nesse sentido possa trazer novos, maiores e mais robustos investidores privados nacionais e estrangeiros para o setor. A participação privada, nesse momento de dificuldade fiscal do setor público, é muito relevante. $\mathrm{O}$ governo precisa reduzir incertezas e fortalecer suas instituições com maior independência para suas agências reguladoras.

\section{Referências}

ACEMOGLU, D.; JOHNSON, S.; ROBINSON, J. A. The colonial origins of comparative development: an empirical investigation. The American Economic Review, v. 91, n. 5, p. 13691401, 2001.

ACEMOGLU, D.; JOHNSON, S.; ROBINSON, J. A. Institutions as a fundamental cause of long-run growth. In: AGHION, P.; DURLAUF, S. N. Handbook of economic growth, v. 1, Amsterdam: Elsevier, 2004.

ACEMOGLU, D.; ROBINSON, J. The role of institutions in growth and development, Commission on Growth and Development Working Paper, n. 10, 2008.

ARENA, R. Modern structural economic dynamics in the short and the long run. Journal of the History of Economic Thought, v. 39, n. 1, p. 101-123, 2017. 
ARROW, K.J. The economic implications of learning by doing. The Review of Economic Studies, v. 29, n. 3, p. 155-173, June 1962.

ASCHAUER, D. Is public expenditure productive? Journal of Monetary Economics, v. 23, p. 177-200, 1989.

BID - BANCO INTERAMERICANO DE DESENVOLVIMENTO. Un nuevo impulso para la integración de la infraestructura regional en América del Sur. Washington: BID, 2000.

BERTUSSI, G. L.; ELLERY JUNIOR, R. Infraestrutura de transporte e crescimento econômico no Brasil. Journal of Transport Literature, v. 6, n. 4, p. 101-132, 2012.

CALDERÓN, C.; SERVÉN, L. The effects of infrastructure development on growth and income distribution. The World Bank Policy Research Working Paper Series, n. 3400, 2004.

COASE, R. The institutional structure of production. The American Economic Review, v. 82, n. 4, 1992.

ECHEVARRIA, C. Changes in sectoral composition associated with economic growth. International Economic Review, v. 38, n. 2, p. 431-452, 1997.

ESTACHE, A.; FAY, M. Current debates on infrastructure policy. World Bank Policy Research Working Paper Series, n. 4410, 2007. Disponível em: http://ssrn.com/abstract=1032030. Acesso em: 03 ago. 2016.

FERREIRA, P. C.; MALLIAGROS, T. G. Impactos produtivos da infra-estrutura no Brasil 1950/95. Pesquisa e Planejamento Econômico, v. 28, n. 2, p. 315-338, 1998.

FREIRE, C. Diversification and structural economic dynamics. 2017. Tese (Doutorado) - Maastricht University, 2017.

GABARDO, F; PEREIMA, J; EINLOFT, P. The incorporation of structural change into growth theory: a historical appraisal. EconomiA, v. 18, n. 3, p. 392-410, 2017.

GUILHOTO, J. J. M. Um modelo computável de equilíbrio geral para planejamento e análise de políticas agrícolas (PAPA) na economia brasileira. 1995. 258 f. Tese (Livre Docência em Economia) - Escola Superior de Agricultura Luiz de Queiroz, Piracicaba, 1995

GUILHOTO, J. J. M.; SESSO FILHO, U. Estimação da matriz insumo-produto a partir de dados preliminares das contas nacionais. Economia Aplicada, v. 9, n. 2, p. 277-299, 2005.

GUILHOTO; SONIS, M.; HEWINGS, G. J. D.; MARTINS, E. B. Índices de ligações e setoreschave na economia brasileira: 1959/80. Pesquisa e Planejamento Econômico, Rio de Janeiro, v. 24, n. 2. p. 287-314, 1994.

HADDAD, E. A.; PEROBELLI, F. S. Mudança estrutural na economia brasileira no período 1985-1996: uma análise de insumo produto. Juiz de Fora: NUPE/UFJF, 2002.

HIRSCHMAN, A. O. Estratégia do desenvolvimento econômico. Rio de Janeiro: Fundo de Cultura, 1961. 
INSTITUTO BRASILEIRO DE GEOGRAFIA E ESTATÍSTICA. Sistema de contas nacionais, tabelas de recursos e usos. Rio de Janeiro: IBGE, 2015.

INSTITUTO BRASILEIRO DE GEOGRAFIA E ESTATÍSTICA. Sistema de contas nacionais, tabelas de recursos e usos. Rio de Janeiro: IBGE, 2017.

LAITNER, J. Structural change and economic growth. The Review of Economic Studies, v. 67, n. 3, p. 545-561, 2000.

LEONTIEF, W. The structure of the American economy. 2nd ed. New York: Oxford University Press; 1951.

LEVY, B.; SPILLER, P. Regulations, institutions, and commitment: comparative studies of telecommunications. Cambridge: Cambridge University Press, 1996.

LUCAS, R. E. On the mechanics of economic development. Journal of Monetary Economics, v. 22, n. 1, 1988.

MCMILLAN, M.; RODRIK, D. Globalization, structural change and productivity growth. NBER Working Paper, n. 17143, 2011.

MILLER, R. E.; BLAIR, P. D. Input-output analysis: foundations and extensions. 2nd ed. Cambridge: Cambridge University Press, 2009, 750 p.

MUSSOLINI, C. C., TELES, V. K. Infraestrutura e produtividade no Brasil. Revista de Economia Política, v. 30, n. 4, p. 645-662, 2010.

NORTH, D., Institutions, institutional change and economic performance. Cambridge: Cambridge University Press, 1990.

OLIVEIRA, M. A. S.; TEIXEIRA, E. C. Infra-estrutura brasileira: identificação de setores chaves para a economia brasileira. In: CONGRESSO DA SOCIEDADE BRASILEIRA DE ECONOMIA, ADMINISTRAÇÃO E SOCIOLOGIA RURAL, 44., 2006, Fortaleza. Anais eletrônicos [...]. Fortaleza: SOBER, 2006.

PASINETTI, L. Structural change and economic growth: a theoretical essay on the dynamics of the wealth of the nations. Cambridge: Cambridge University Press, 1981.

PASINETTI, L. Structural economic dynamics: a theory of the economic consequences of human learning. Cambridge: Cambridge University Press, 1993.

RASMUSSEN, P. Studies in intersectoral relations. Amsterdam: North Holland, 1956.

ROMER, P. Increasing returns and long run growth. Journal of Political Economy, v. 94, n. 5, 1986.

ROMER, P. Endogenous technological changes. Journal of Political Economy, v. 98, n. 5, 1990.

SAMUELSON, P. A summing up. Quarterly Journal of Economics, v. 80, n. 4, p. 568-583, 1966. 
SAVIOTTI P-P., PYKA A. Economic development by the creation of new sectors. Journal of Evolutionary Economics, v. 14, n. 1, p. 1-35, 2004.

SOLOW, R. M. A contribution to the theory of economic growth. Quarterly Journal of Economics, v. 70, n. 1, p. 65-94, 1956.

TOSTA, M. C. R.; LÍRIO, V. S.; SILVEIRA, S. F. R. Matrizes de insumo-produto: construção, uso e aplicações. In: SANTOS, M. L.; VIEIRA, W. C. Métodos quantitativos em economia. Viçosa: UFV, 2004, p. 140-180.

TOYOSHIMA, S.; FERREIRA, M. J. Encadeamento do setor de transportes na economia brasileira. Planejamento e Políticas Públicas, n. 25, 2002.

\section{Autor correspondente:}

Geovana Lorena Bertussi

Recebido em: 11/09/2017.

E-mail: geovanalorena@gmail.com Aceito em: 29/04/2019. 